\title{
Managing Sustainable Design for Geothermal Plants: the Engineer’s Perspective
}

\author{
Chun Chin ${ }^{1, *}$, Joshua Gunderson ${ }^{1}$, Joe Stippel ${ }^{1}$, Matt Fishman ${ }^{1}$, Gudrun Saevarsdottir ${ }^{2}$, \\ William Harvey ${ }^{2}$ \\ ${ }^{1}$ POWER Engineers, Hailey Idaho, USA \\ ${ }^{2}$ Reykjavik University, Reykjavik, Iceland \\ * Corresponding author.Tel: +001 2087880527,E-mail:cchin@powereng.com
}

\begin{abstract}
The fast pace of project development, design, and execution of power generation projects, together with the nature of Engineering-Procurement-Construction (EPC) contracts popular in the industry and to banks, often make sustainability considerations a grudging afterthought to the contractor or owner. Although careful consideration of technical, environmental, and social impacts may have been part of the up-front permitting process, the control wielded by skilled engineers during the detailed design process, if implemented in an educated and structured fashion with the owner, and in an EPC environment, with buy-in from the contractor, can result in plant designs that better benefit the local community in dimensions beyond thermal efficiency. This paper will present a structured review process developed by the authors, which is targeted toward the specific considerations of geothermal power projects. This procedure may be applied to other renewable projects, especially those with similarly complex processing systems such as biofuel refineries or solar thermal projects. The review process is performed with the owner and is documented to demonstrate upon completion the project's commitment to sustainable principles. These audit principles provide a platform to educate owners on topics such as alternative methods of construction best suited to the local conditions, workforce, and carbon footprint; project management structures to maximize local content and knowledge transfer, and assessment of all resource and revenue streams from the plant in addition to electrical production. The paper describes the way in which geothermal plants have and require a closer relationship with the local community, and strengthening this relationship is the goal of these processes.
\end{abstract}

Keywords: Geothermal, Sustainability reviews, Local content, Project management.

\section{Introduction}

The nature of geothermal projects, with their wide range of resource conditions and variety of material and revenue streams, render them more complex cases than many other "plug and play" fossil or renewable generation options. While careful consideration of technical, environmental, and social impacts may have been part of the up-front environmental and local permitting processes, these are often managed by developers and government agencies more focused on establishing the viability of the overall project than optimization of sustainability features. These features may include selection of equipment with lower energy requirements or greater local involvement, such as materials of construction for cooling towers, or use of byproduct streams for maximum benefit, such as recovered sulphur for fertilizers. The time and incentive to focus on sustainability features is diminished by the tendency for many of these projects to be executed under financing structures that discourage value engineering. This paper presents a method to integrate sustainability considerations more systematically into plant design.

This paper presents a structured audit and review process developed by the authors, based on the principles of sustainable development and their experience with geothermal projects, with case studies from locations in the developing world. The review process is targeted toward the specific considerations of geothermal power projects, performed with the owner, and documented to demonstrate upon completion the project's contributions to sustainable principles and community acceptance. These audit principles provide a platform to educate owners on topics such as alternative methods and materials of construction best suited to the 
local conditions, best integration of local workforce for initial construction and O\&M activities; reducing carbon and land footprint; project management structures to maximize local content and knowledge transfer, and assessment of multiple potential resource and revenue streams from the plant. This process represents a minor investment for the owner, makes best use of the talent available in the design phase, and is executed in the appropriate stage of development for greatest impact at least cost. Pitfalls will be discussed along with ways in which the review can be customized to suit the needs of various owners. Structured sustainability reviews will result in designs that harness the resource more fully, respect the owner's constraints, and contribute to greater project success.

The remainder of the Introduction section will discuss considerations of project execution and financing constraints specific to geothermal plants. The Methodology section will describe the timing and structure of sustainability audits developed by the authors for geothermal projects. The Results section will describe several case studies of how these audit principles have been applied successfully.

\subsection{Geothermal Project Development}

Geothermal plants, while lacking the aerodynamic sleekness of wind projects or the cutting edge science of photovoltaics, nevertheless can be major contributors to a country's renewable energy portfolio, providing dispatchable, reliable baseload power unaffected by the vagaries of fuel costs and environmental conditions. In developing countries such as Nicaragua and Kenya, geothermal offers the potential to completely displace fossil fuel generation as the lowest cost alternative.

While the capital costs of these projects may be substantial - perhaps $\$ 3,000$ to $\$ 5,000$ per $\mathrm{kW}$ of installed capacity - they also include the up-front "fuel costs" of well drilling. This high initial cost is further mitigated by the fact that geothermal plants operate at high capacity factors, routinely exceeding $90 \%$.

A typical geothermal project encompasses three major areas:

- the reservoir, from which the hot geofluid (steam or water) is drawn and spent fluid returned,

- the gathering system, where the collected geofluid is conveyed from production wells to the plant and returned to injection wells, and

- the power plant, where power is generated from the geofluid by a variety of methods, most commonly flash (directly driving steam through a turbine) or binary (using the geofluid to vaporize a secondary working fluid, often a hydrocarbon, which passes through the turbine).

The characterization and exploration of the geothermal reservoir is a task that may take years and require the efforts of a dedicated team of geoscientists. Even with the best estimates, the production capacity of a geothermal field is generally uncertain until several wells have been drilled and proven. Until sufficient capacity has been proven, often to a significant percentage of the required plant capacity and typically above 50\%, banks are generally unwilling to finance the project. For this reason, exploration is generally funded with equity from a developer which may amount to a considerable sum; a typical 50 MW plant may require an investment of $\$ 15$ million of equity before loans can be obtained [1]. However, with proven wells and the requisite permits in place, the developer turns quickly to the challenge of designing and financing the project in preparation for construction. 


\subsection{Project Structures for Execution}

The traditional structure for utility projects has historically been a Design-Bid-Build (D/B/B) approach, where the Owner will engage an Engineer to carry out the detailed design. The Owner and Engineer work collaboratively to define the design criteria, design the process, and specify equipment. Purchase orders for equipment are placed by the Owner. After approximately $60 \%$ of the design is complete, construction specifications for bidding by Contractors are prepared, where the Contractor will place orders for bulk materials and carry out the requisite work. The advantages of the $\mathrm{D} / \mathrm{B} / \mathrm{B}$ approach are that the Owner maintains firm control over the design process, avoids Contractor markups on major equipment, and the project schedule can be shorter than alternative project delivery methods. One disadvantage is that the firm project cost is not known until later in the process, which makes $\mathrm{D} / \mathrm{B} / \mathrm{B}$ less appealing for financiers. The Engineer might prefer a D/B/B approach because it leaves more room for value engineering and sustainability considerations in collaboration with the Owner. However, narrowly focused financial considerations are leading to an increase in projects that must be executed under an "EPC" approach, discussed next.

An Engineering-Procurement-Construction (EPC) approach is more favored by financiers, although the financial benefits are balanced by certain complications. The Owner begins by preparing a fairly detailed performance specification. An EPC Contractor then gives a firm lump sum bid backed by schedule and performance guarantees. This process is time intensive, leading to EPC projects generally being at least 4-6 months longer than a well executed D/B/B approach. Next, the Contractor engages an Engineer to perform the detailed design and the Contractor places the purchase orders for major equipment. The advantage of the EPC approach is ease of financing due to the Owner's financier having a firm price and performance/schedule guarantees at the beginning of the project. Disadvantages include less Owner control over the evolution of the design, since it is constrained only by the initial specifications; higher cost, due to additional markups and risk burden on the Contractor; and generally longer schedule due to the lengthier contract negotiations and some redundancy in design effort between the Owner and Contractor.

The initial phase of conceptual design by an EPC Contractor/Engineer team generally consists of several months of equipment specification and procurement, the goal being to award purchase orders for the critical path items that define the overall project schedule and impact the design of foundations and supporting subsystems. These major plant items include the turbine/generator, condenser, cooling tower, non-condensible gas removal system, and major pumps. These all will be ordered generally within four to six months after EPC contract award.

The opportunity to explore plant improvements that would improve sustainability attributes can be inhibited by the EPC approach. The contract is generally awarded to the lowest bidder; discouraging the search for solutions that may have greater long-term value. After award, the Contractor generally faces liquidated damages for schedule delays, hence they and the Engineer are considerably motivated to avoid proposing investigation of upgrade opportunities. Finally, the lump sum contract would require renegotiation in the event that the Contractor proposes investments in upgrades. All these, along with the rapid pace of design and construction, are disincentives to thoughtful plant optimization under the EPC approach. 


\section{Methodology}

\subsection{Timing of the Sustainability Review}

The Engineer faces the challenge of how to incorporate sustainability considerations swiftly, appropriately, and in a win-win approach with the Owner and Contractor, which may have competing interests. The methodology developed by the authors incorporates a Sustainability Review into a natural Owner and Contractor design review process that generally occurs after 3-4 months for a typical project. In this design review the conceptual-level documents are reviewed for adequacy and conformance with the project specifications. At this time it is also common to hold a Process Hazard Analysis (PHA), or Hazard and Operability Study (HAZOP), which is a structured "what-if" review of the conceptual documents to explore the possibilities to improve safety. HAZOP reviews were originally developed for the chemical industry, and conducting these is often an Owner or regulatory requirement for a complex processing plant, such as a geothermal project, with its multitude of fluids and flows. The expansion of 'binary' technologies, which can be used in geothermal, ocean thermal, and solar thermal projects, generally call for HAZOPs since they often incorporate hydrocarbon working fluids. The Sustainability Review we have developed is scheduled at the same time and has a similar structure to the HAZOP.

\subsection{Objectives of the Sustainability Review}

The Bellagio Principles [3] are used as guidance, which emphasize among others clear goal setting, a holistic perspective, considerations of economic and non-economic principles, local and regional effects, short and long-term effects, and a focus on practical goals. The objective of the Sustainability Review is to emerge from the process with:

- Clear direction from the Owner and agreement with Contractor on any specification, contract, or schedule modifications required to enhance sustainable attributes.

- Written documentation describing the steps Owner, Contractor, and Engineer have taken to be mindful of sustainability considerations, in a format suitable for dissemination to the public if the Owner so chooses.

- An expectation that future changes will be minimized so as to protect the Contractor's project schedule and ongoing design.

\subsection{Structure of the Sustainability Review}

The proposed Sustainability Review process can be submitted to proposed EPC clients as part of the proposal documentation for consideration according to their green values. This is treated as a value-adding cost option, so that it is appreciated in its own right, and yet does not jeopardize winning an EPC project by building in costs that other bidders may not have allocated. If the project is a win, the Engineer works with the Owner and Contractor to make selections consistent with their philosophy on sustainability.

During the initial conceptual design phase, a preliminary project sustainability report is generated; typically at around the 3 month time frame and prior to the Design Review/HAZOP/Sustainability Review sessions. This provides an agenda and some suggested topics of discussion for the Review. Each proposed aspect should be developed with the following considerations in mind:

1. The Engineer's role is to educate and inform; the Owner and Contractor will be the final arbiters.

2. Must be mindful of the client's own sustainable charter. 
3. Must sell on its own merit such that cost benefits, positive environmental impacts, better integration with the surrounding community and other intangible benefits make the program attractive.

4. Must be easy to understand, clearly defined (can be organized by system, discipline or combination thereof) and practical for implementation.

5. Positive impacts to the environment as well as a business case and cost justification must be measurable and presentable to both the Owner and Contractor

6. Flexibility in the program will allow clients to have the freedom to choose the weighted aspects of sustainability they want their project to possess.

7. Conduct risk assessments and comparative studies to show how an innovative technology compares with traditional technologies.

Following the Sustainability Review, a Sustainability Report is generated as part of the project record documentation, identifying the areas of positive impact and stating both one time and recurring benefits.

The effort involved in preparing for and executing the Sustainability Review is not inconsiderable, but the impact on even small subsystems can be substantial. Compare a scenario where 10 workdays are spent in preparation, 20 workdays for an attendance of ten representatives for two days of the review, and 10 workdays for preparation of the summary report. This may come to some tens of thousands of dollars for a dedicated review. Yet, identifying even small efficiency upgrades or locally, less expensive materials can be tremendously impactful. Plant output may be assessed with net present values in the $\$ 4000 / \mathrm{kW}$ range, meaning a $1 \%$ identified efficiency improvement on a $1000 \mathrm{~kW}$ pump/motor may cover the cost of the study. Similarly, the cost of a single imported stainless steel large diameter flange may exceed \$20,000; alternative materials, layouts, or suppliers permitted by the Owner may result in significant cost savings. Also, design modifications that reduce environmental impact may have long term value for the Owner in terms of local acceptance of the project.

\subsection{Methodology of the Sustainability Review}

Similar to a HAZOP study, the Sustainability Review is designed to promote discussion and generation of ideas by being open ended. Specific suggestions may be covered in the preliminary report, if some research is required, but other ideas may be generated by the participants during the meeting. A full and comprehensive review meeting may last for several days and require an interdisciplinary and interparty team of 5-15 people, but an abbreviated review can be performed with a smaller group of stakeholder participants.

Natural divisions consistent with plant design may be used to facilitate an organized search for potential sustainability features. Primary divisions may be based on engineering disciplines such as Architectural, Civil, Structural, Mechanical, Electrical, and Controls. Each discipline brings to the review key deliverables such as Process Flow Diagrams, Electrical One-Line Diagrams, or General Arrangement Drawings. A set of key plant areas, systems, or equipment that merits study is developed. The team brainstorms to come up with alternative configurations within the area/system/equipment. Then each alternative is evaluated with regard to sustainability attributes and metrics. The following are sample parameters to be discussed and assessed with a weighted score.

- Environmental: Green/LEED structures, provide animal crossings, minimize chemical waste streams or improve disposal practices. 
- Social: Use local labor and locally supplied materials. Innovative designs that appeal to the public while improving sustainability (geothermal heating, energy efficient lighting, passive solar, novel waste heat utilization), reduce noise levels.

- Health \& Safety: Minimize use of hazardous materials. Use safer construction practices and materials.

- Diversity: Consider how alternatives may contribute to the diversity of organisms or institutions that benefit from its application.

- Natural Resources: Minimize land use. Minimize water use. Utilize waste streams.

- Human Resources: Make changes to facilities to improve workforce morale (covered walkways, breakrooms, better maintenance access ways, etc.)

- Engineering and Procurement: Increase efficiency due to alternative materials, equipment type, layout, or other design parameters. Improve off-design and turndown capabilities. Shorten the procurement cycle.

- Construction: Compress project schedule with changes to equipment, layout, materials, etc. Use locally available materials and construction techniques.

- Availability: Add equipment redundancy where appropriate. Review single points of failure.

- Operations: Consider alternatives to improve operator experience, ease of troubleshooting, etc.

- Maintenance: Evaluate impact on maintenance frequency, cost, need for specialists.

A typical Sustainability Review process is outlined in the appendix. Each suggestion for improvement is reviewed against the tender specifications to verify that it is not already a mandatory requirement. The cost of any suggested enhancement is assessed or tagged for further study. Within several weeks the facilitator prepares a report of the suggested upgrades, the proposed costs, and any schedule adjustments. Those options that are implemented and other observations such as plant benefits to the local community are documented in the report in a manner sufficient for use by the Owner to demonstrate their commitment to sustainable principles. The usefulness of this procedure would not necessarily be limited to powerplants; other similar renewable energy projects such as a biofuel synthesis facility could be studied with these techniques.

\section{Case Studies}

Through reviews such as these, several modifications leading to improved sustainability aspects have been successfully implemented in geothermal projects around the world.

Darajat II, Indonesia: This 110 MW geothermal plant houses the world's largest single pressure geothermal turbine. During reviews between the Owner, Contractor, and Engineer of the Darajat II project, it was revealed that several workers had died during the construction of the Darajat I concrete cooling tower some years earlier by a different team. Although a change in the style of construction of the tower was not a contract requirement, the Contractor and Engineer shifted from a cast-in-place concrete cooling tower to a precast design, where forms were set on grade and pieces lifted into place similar to the erection of a massive log building. This had not been attempted before on a geothermal project, and posed POWER Engineers and the cooling tower manufacturer, SPX, with several new challenges. Nevertheless, the tower was constructed without a major construction incident. Ironically the Contractor's project manager, who proposed the modification, lost his life due to illness during the project; the tower is a memorial of sorts. 
Germencik, Turkey: This 47.4 MW unit is the largest geothermal plant in Turkey. A decision was made in the design phase to maximize the use of local subcontractors and materials, with consideration that in Turkey little geothermal-specific design expertise existed. A division of labor for the systems was developed that allowed specialist firms to design such items as the powerhouse layout and structural steel required to support equipment and piping, given certain critical loads, while Turkish firms familiar with locally available architectural styles and fixtures completed the detailed design of the façade. A list of structural shapes commonly available in Turkey was provided to POWER Engineers and preferentially used in the steel design to minimize the need for importation [4].

San Jacinto II, Nicaragua: These 2 x 38.5 MW flash plants currently under construction will add $10 \%$ of renewable capacity to Nicaragua's total generation of $750 \mathrm{MW}$, displacing about one million barrels of diesel fuel per year. Due to challenging construction conditions and a local scarcity of construction equipment such as augers, several modifications were made to reduce the size and depth of foundations associated with the major pumps, shortening the construction period and reducing concrete quantities. A shift was made from galvanized steel structures to wider use of painting to resist corrosion, in a desire to reduce imports due to a local scarcity of galvanizing facilities.

\section{Conclusion}

The rushed pace of project execution, especially for EPC contracts, make incorporation of sustainability considerations a challenge for the engineer. However, the customization of each geothermal plant, required due to the unique nature of each resource, means some time should be allocated to explore new opportunities for each project. Addressing these at the appropriate time during the conceptual design phase or early detailed design phase, and doing so with a structured process between the Owner, Contractor, and Engineer, is necessary for the right ideas to find expression in the plant design. The metrics to be applied and the appropriate weightings are parameters that may change for each project; better quantifying and handling of these is an avenue for future work. Documenting the decisions made and the potential positive impacts the plant can bring to the local community can improve the relationship between the Owner and local resources including workers and policy makers, making ongoing plant modifications or expansions (a common occurrence when new fields are incrementally developed) a smoother process. The review process suggested here is intended to bring more of these considerations into the awareness of the various parties, and may be extended for use to other sorts of analogous renewable projects.

\section{References}

[1] Deloitte, Geothermal Risk Mitigation Strategies Report, Prepared for the DOE Office of Energy Efficiency and Renewable Energy Geothermal Program. 2008.

[2] P. Hardi and T. Zdan, Assessing Sustainable Development: Principles in Practice, International Institute for Sustainable Development, 1997.

[3] International Hydropower Association, Sustainability Assessment Protocol, 2006.

[4] T. Dunford, M. Fishman, K. Wallace, M. Ralph, and W. Harvey, Engineering Local Value: Case Studies from Olkaria and Beyond. GRC Transactions, Vol. 34, 2010, pp. 186-190. 


\section{Appendix: Sample Sustainability Audit Process}

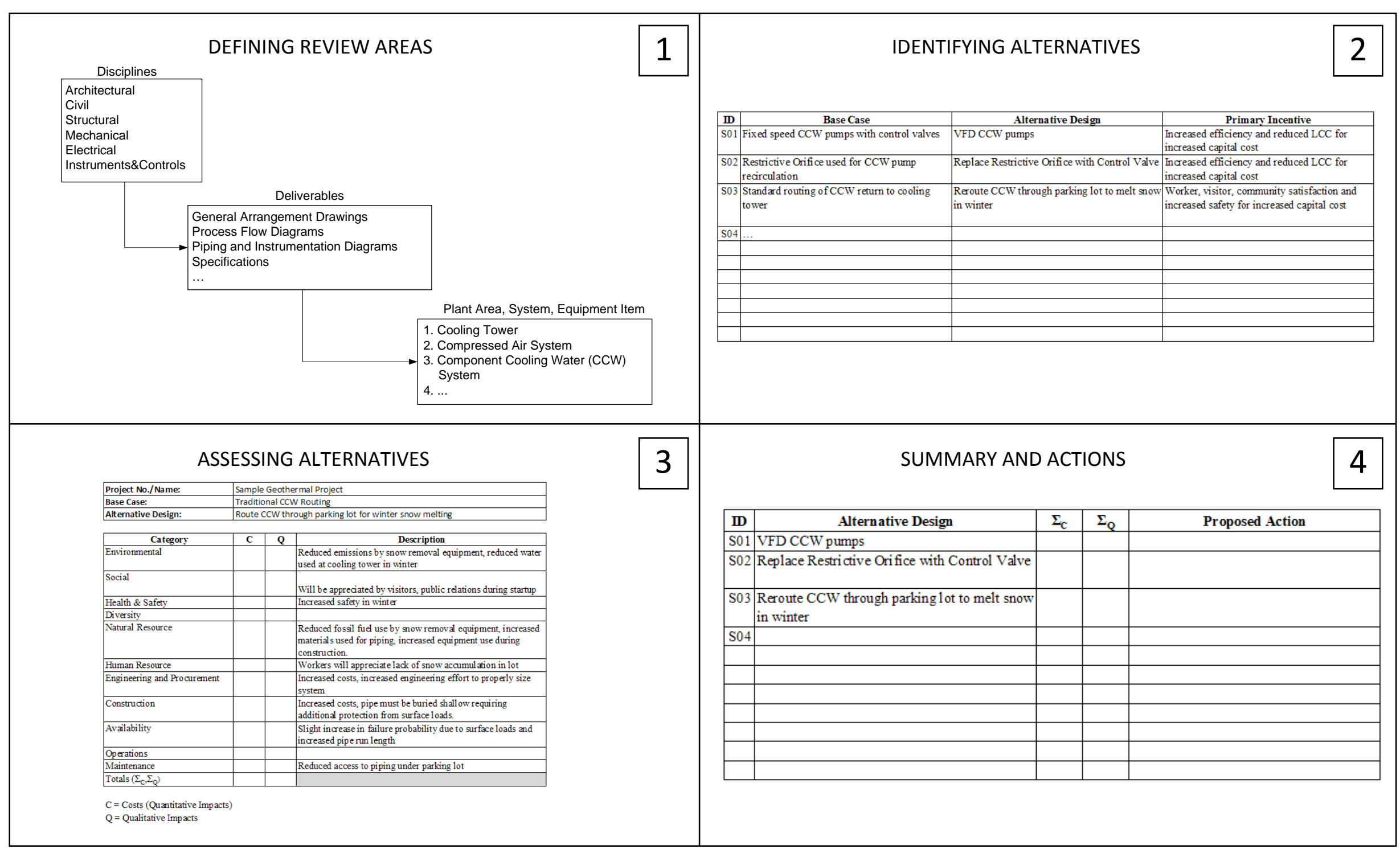

